\title{
Mathematical model of electrical system including transformer and electrical drives based on induction motors and synchronous motors
}

\author{
Marek Lis ${ }^{1, *}$, and Andriy Chaban ${ }^{2}$ \\ ${ }^{1}$ Czestochowa University of Technology, Faculty of Electrical Engineering, Poland \\ ${ }^{2}$ University of Technology and Humanities in Radom, Faculty of Transport and Electrical \\ Engineering, Poland
}

\begin{abstract}
On the basis of interdisciplinary modelling methods the mathematical model of the electromechanical system, including power transformer, induction motors and synchronous motors, is formulated and presented in the paper. The motors are joined with the driven objects through a mechanical power transmission system. In addition, the transformer is loaded by nonlinear circuit RL. Differential state equations of the studied system are given as the Cauchy's formulas. Numerical simulations of the system operation have been made for the selected cases. The results of computer simulation are presented in a graphic form.
\end{abstract}

\section{Introduction}

An interdisciplinary variational method has been used in order to formulate a general mathematical model of an electrical system. The method is based on a modification of Hamilton's principle $[1,4]$. The electromechanical system including transformer, induction motors and synchronous motors as well as nonlinear load RL is analysed. Differential equations describing operation state of the system are derived by formulation of modified Lagrangian terms using the abovementioned method [2, 3].

\section{Mathematical model of the system}

The electric diagram of the analysed system is depicted in Fig. 1. In general case the system is consisted of $k$ electric drives, where $k_{1}$ is number of induction machines and $k_{2}=k-k_{1}$ is number of synchronous machines.

The modified Lagrange's function $L^{*}$ is given as follows:

$$
L^{*}=\tilde{T}^{*}-P^{*}+\Phi^{*}-D^{*},
$$

\footnotetext{
${ }^{*}$ Corresponding author: lism@el.pcz.czest.pl
} 
where: $\tilde{T}^{*}$ is kinetic coenergy, $P^{*}$ is potential energy, $\Phi^{*}$ is dissipation energy, $D^{*}$ is work of external forces [1].

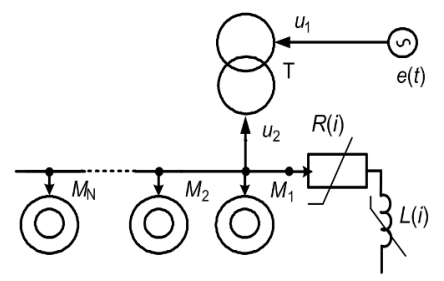

Fig. 1. The diagram of the studied equipment assembly configuration.

The following quantities are adopted as generalized coordinates:

- electric charges in stator windings of induction motors: $q_{(1-3), k}=Q_{S A, k}, Q_{S B, k}, Q_{S C, k}$, $k=1, \ldots, N$ and rotor windings of induction motors: $q_{(4-6), k_{1}}=Q_{R A, k_{1}}, Q_{R B, k_{1}}, Q_{R C, k_{1}}, k_{1}=1, \ldots, M$ and stator windings of synchronous motors: $q_{(4-6), k_{2}}=Q_{D, k_{2}}, Q_{Q, k_{2}}, Q_{f, k_{2}}, k_{2}=M+1, \ldots, N$, - angles of rotor rotation $\left(\gamma_{1}\right)$ and rotating masses $\left(\gamma_{2}\right)$ for all drives: $q_{7, k}=\gamma_{1, k}, q_{8, k}=\gamma_{2, k}$, - electrical charges in transformer windings: $q_{(9-14)}=Q_{1 A}, Q_{1 B}, Q_{1 C}, Q_{2 A}, Q_{2 B}, Q_{2 C}$

- electrical charges in nonlinear load circuit on transformer secondary: $q_{(15-17)}=Q_{L A}, Q_{L B}, Q_{L C}$. The following quantities are adopted as generalized velocities: $\dot{q}_{(1-3), k}=i_{S A, k}, i_{S B, k}, i_{S C, k}$, $\dot{q}_{(4-6), k_{1}}=i_{R A, k_{1}}, i_{R B, k_{1}}, i_{R C, k_{1}}, \quad \dot{q}_{(4-6), k_{2}}=i_{D, k_{2}}, i_{Q, k_{2}}, i_{f, k_{2}}, \quad \dot{q}_{7, k}=\omega_{1, k}, \dot{q}_{8, k}=\omega_{2, k}$, $\dot{q}_{(9-14)}=i_{1 A}, i_{1 B}, i_{1 C}, i_{2 A}, i_{2 B}, i_{2 C}, \dot{q}_{(15-17)}=i_{L A}, i_{L B}, i_{L C}$. The terms of modified Lagrangian for the considered power system (Fig. 1) are described as follows:

$$
\begin{aligned}
& \tilde{T}^{*}=\tilde{T}_{E}^{*}+\tilde{T}_{M}^{*}=\sum_{j=1}^{3}\left[\int_{0}^{i_{1 j}} \Psi_{1 j} d i_{1 j}+\int_{0}^{i_{2 j}} \Psi_{2 j} d i_{2 j}+\int_{0}^{i_{L j}} \Psi_{L j} d i_{L j}\right]+ \\
&+\sum_{k=1}^{N}\left(\sum_{j=1}^{3} \int_{0}^{i_{S j, k}} \Psi_{S j, k} d i_{S j, k}+\sum_{i=1}^{2} \frac{J_{i, k} \omega_{i, k}^{2}}{2}\right)+\sum_{k_{1}=1}^{M} \sum_{j=1}^{3} \int_{0}^{i_{R j, k_{1}}} \Psi_{R j, k_{1}} d i_{R j, k_{1}}+ \\
&\left.+\sum_{k_{2}=}^{N} \Psi_{+1} \int_{0}^{i_{D, k_{2}}} \Psi_{D, k_{2}} d i_{D, k_{2}}+\int_{0}^{i_{Q, k_{2}}} \Psi_{Q, k_{2}} d i_{Q, k_{2}}+\int_{0}^{i_{f, k_{2}}} \Psi_{f, k_{2}} d i_{f, k_{2}}\right) \\
& P^{*}=\frac{1}{2} \sum_{k=1}^{N} c_{k}\left(\gamma_{2, k}-\gamma_{1, k}\right)^{2}, \Phi^{*}=\frac{1}{2} \int_{0}^{t} \sum_{k=1}^{N} v_{k}\left(\omega_{2, k}-\omega_{1, k}\right)^{2} d \tau+ \\
&+\sum_{j=1}^{3}\left(\frac{1}{2} \int_{0}^{t}\left(r_{1 j} i_{1 j}^{2}+r_{2 j} i_{2 j}^{2}\right) d \tau+\int_{0}^{t} \int_{0}^{i_{L}} r_{L}\left(i_{L}\right) i_{L} d i_{L} d \tau\right)+ \\
&+\frac{1}{2} \sum_{k=1}^{N} \sum_{j=1}^{3} \int_{0}^{t} r_{S j, k} i_{S j, k}^{2} d \tau+\frac{1}{2} \sum_{k_{1}=1}^{M} \sum_{j=1}^{3} \int_{0}^{t} r_{R L, k_{1}} i_{R j, k_{1}}^{2} d \tau+
\end{aligned}
$$




$$
\begin{aligned}
& \left.+\frac{1}{2} \sum_{k_{2}=M+1}^{N} \int_{0}^{t} \int_{D, k_{2}} i_{D, k_{2}}^{2} d \tau+\int_{0}^{t} r_{Q, k_{2}} i_{Q, k_{2}}^{2} d \tau+\int_{0}^{t} r_{f, k_{2}} i_{f, k_{2}}^{2} d \tau\right) \\
& D^{*}=\sum_{j=1}^{3} \int_{0}^{t}\left(u_{1 j} i_{1 j}+u_{2 j} i_{2 j}-u_{2 j} i_{L j}\right) d \tau+\sum_{k_{2}=M+1}^{N} \int_{0}^{t} u_{f, k_{2}} i_{f, k_{2}} d \tau- \\
& \quad-\sum_{k_{1}=1}^{M} \sum_{j=1}^{3} \int_{0}^{t} u_{R j, k_{1}} i_{R j, k_{1}} d \tau+\sum_{k=1}^{N}\left(\sum_{j=1}^{3} \int_{0}^{t} u_{2 j} i_{S j, k} d \tau-\right. \\
& \left.\quad-\int_{0}^{t} \int_{0}^{\omega_{k}} M\left(\omega_{k}\right) d \omega_{k} d \tau\right), \quad P^{*}=0, \quad j=A, B, C
\end{aligned}
$$

where: $\boldsymbol{\Psi}_{1}, \boldsymbol{\Psi}_{2}$ are column vectors including full flux linkages of primary and secondary windings of transformer, $\mathbf{r}_{1}, \mathbf{r}_{2}$ are matrixes including resistances of primary and secondary windings of transformer, $\mathbf{i}_{1}, \mathbf{i}_{2}$ are column vectors including currents, $\mathbf{u}_{1}, \mathbf{u}_{2}$ column vectors including voltages, for indexes ${ }_{S, R, f, D, Q}$ these deal with windings of all motors, $i_{L}$ is current of nonlinear load, $c, v$ are coefficients of both elasticity and dissipation of elastic clutches of all drives, $M_{E M, k}$ are electromagnetic torques of motors, $M\left(\omega_{k}\right)$ are load torques applied to the shafts of motors.

$$
M_{E M}=\frac{\partial\left[\tilde{T}_{E}^{*}\right]}{\partial \gamma}
$$

Subsequently, the action functional and its variations for the analysed system have been derived, then the equations of extremal function of functional have been derived as a consequence of adequate mathematic conversion $[1,2,8]$.

$$
\begin{aligned}
& \frac{d \boldsymbol{\Psi}_{1}}{d t}=\mathbf{u}_{1}-\mathbf{r}_{1} \mathbf{i}_{1}, \frac{d \boldsymbol{\Psi}_{2}}{d t}=\mathbf{u}_{2}-\mathbf{r}_{2} \mathbf{i}_{2}, \frac{d \boldsymbol{\Psi}_{L}}{d t}=\mathbf{u}_{2}-\mathbf{R}\left(\mathbf{i}_{L}\right) \mathbf{i}_{L}, \\
& \frac{d \boldsymbol{\Psi}_{S, k}}{d t}=\mathbf{u}_{2}-\mathbf{r}_{S, k} \mathbf{i}_{S, k}, \frac{d \boldsymbol{\Psi}_{R, k_{1}}}{d t}=-\mathbf{u}_{\mathrm{R}, k_{1}}-\mathbf{r}_{R L, k_{1}} \mathbf{i}_{R, k_{1}}, \\
& \frac{d \boldsymbol{\Psi}_{R, k_{2}}}{d t}=\mathbf{u}_{R, k_{2}}-\mathbf{r}_{R, k_{2}} \mathbf{i}_{R, k_{2}}, \quad k_{1}=1, \ldots, M, k_{2}=M+1, \ldots, N, \\
& \frac{d \omega_{1, k}}{d t}=\frac{1}{J_{1, k}}\left(M_{E M, k}+c_{k}\left(\gamma_{2, k}-\gamma_{1, k}\right)+v_{k}\left(\omega_{2, k}-\omega_{1, k}\right)\right), \\
& \frac{d \omega_{2, k}}{d t}=-\frac{1}{J_{2, k}}\left(c_{k}\left(\gamma_{2, k}-\gamma_{1, k}\right)+v_{k}\left(\omega_{2, k}-\omega_{1, k}\right)+M(\omega)_{, k}\right), \\
& \frac{d \gamma_{1, k}}{d t}=\omega_{1, k}, \frac{d \gamma_{2, k}}{d t}=\omega_{2, k}, \quad k=1, \ldots, N .
\end{aligned}
$$

where: $k_{1}$ deals with induction motors and $k_{2}$ deals with synchronous motors.

Taking into account the following dependencies $[1,7]$ : 


$$
\begin{aligned}
& \boldsymbol{\Psi}_{1}=\boldsymbol{\alpha}_{\sigma 1}^{-1} \mathbf{i}_{1}+\boldsymbol{\psi}, \quad \boldsymbol{\Psi}_{2}=\boldsymbol{\alpha}_{\sigma 2}^{-1} \mathbf{i}_{2}+\boldsymbol{\psi}, \quad \boldsymbol{\psi}=\boldsymbol{\tau}^{-1}\left(\mathbf{i}_{1}+\mathbf{i}_{2}\right), \\
& \boldsymbol{\Psi}_{S, k}=\boldsymbol{\alpha}_{\sigma S, k}^{-1} \mathbf{i}_{S, k}+\boldsymbol{\Psi}_{S, k}, \boldsymbol{\Psi}_{R, k_{1}}=\boldsymbol{\alpha}_{\sigma R L, k_{1}}^{-1} \mathbf{i}_{R, k_{1}}+\boldsymbol{\psi}_{R, k_{1}}, \\
& \boldsymbol{\Psi}_{S, k_{1}}=\boldsymbol{\Psi}_{k_{1}}, \boldsymbol{\Psi}_{S, k_{2}}=\boldsymbol{\Pi}_{1, k_{2}}^{-1} \boldsymbol{\Psi}_{k_{2}}, \quad \boldsymbol{\Psi}_{R, k_{2}}=\mathbf{B} \boldsymbol{\psi}_{k_{2}}, \\
& \mathbf{i}=\mathbf{i}_{1}+\mathbf{i}_{2}, \mathbf{i}_{k_{1}}=\mathbf{i}_{S_{k_{1}}}+\boldsymbol{\Pi}_{k_{1}} \mathbf{i}_{k_{k_{1}}}, \mathbf{i}_{k_{2}}=\boldsymbol{\Pi}_{1, k_{2}} \mathbf{i}_{S_{k_{2}}}+\mathbf{B}^{\mathrm{T}} \mathbf{i}_{R_{k_{2}}}, \\
& \boldsymbol{\Psi}_{k_{1}}=\tau_{k_{1}}^{-1}\left(\mathbf{i}_{S_{k_{1}}}+\boldsymbol{\Pi}_{k_{1}} \mathbf{i}_{R_{k_{1}}}\right), \boldsymbol{\Psi}_{k_{2}}=\boldsymbol{\tau}_{k_{2}}^{-1}\left(\boldsymbol{\Pi}_{1, k_{2}} \mathbf{i}_{S_{k_{2}}}+\mathbf{B}^{\mathrm{T}} \mathbf{i}_{R_{k_{2}}}\right) .
\end{aligned}
$$

where: $\boldsymbol{\psi}$ is matrix of magnetic linkages (for transformer and motors), $\boldsymbol{\tau}$ is matrix of reverse magnetization inductances, $\mathbf{B}$ is topology matrix, $\boldsymbol{\Pi}$ is oblique transformation matrix, $\boldsymbol{\Pi}_{1}$ is Park transformation matrix,

the mathematical model of the system referenced to the current coordinates has been obtained $[1,4,9]$

$$
\begin{aligned}
& \frac{d \mathbf{i}_{1}}{d t}=\mathbf{A}_{1}\left(\mathbf{u}_{1}-\mathbf{r}_{1} \mathbf{i}_{1}\right)+\mathbf{A}_{12}\left(\mathbf{u}_{1}-\mathbf{r}_{2} \mathbf{i}_{2}\right) \\
& \frac{d \mathbf{i}_{2}}{d t}=\mathbf{A}_{21}\left(\mathbf{u}_{1}-\mathbf{r}_{1} \mathbf{i}_{1}\right)+\mathbf{A}_{2}\left(\mathbf{u}_{2}-\mathbf{r}_{2} \mathbf{i}_{2}\right) \\
& \frac{d \mathbf{i}_{S, k_{1}}}{d t}=\mathbf{A}_{S, k_{1}}\left(\mathbf{u}_{2}-\mathbf{r}_{S, k_{1}} \mathbf{i}_{S, k_{1}}\right)+ \\
& +\mathbf{A}_{S R, k_{1}}\left(-\mathbf{u}_{R, k_{1}}-\mathbf{\Omega}_{k_{1}} \mathbf{\Psi}_{R, k_{1}}-\mathbf{r}_{R, k_{1}} \mathbf{i}_{R, k_{1}}\right) \\
& \frac{d \mathbf{i}_{R, k_{1}}}{d t}=\mathbf{A}_{R S, k_{1}}\left(\mathbf{u}_{2}-\mathbf{r}_{S, k_{1}} \mathbf{i}_{S, k_{1}}\right)+\mathbf{A}_{R, k_{1}}\left(-\mathbf{u}_{R, k_{1}}-\right. \\
& \left.-\mathbf{\Omega}_{k_{1}} \mathbf{\Psi}_{R, k_{1}}-\mathbf{r}_{R L, k_{1}} \mathbf{i}_{R, k_{1}}\right)+\boldsymbol{\Omega}_{k_{1}} \mathbf{i}_{R, k_{1}} \\
& \frac{d \mathbf{i}_{S, k_{2}}}{d t}=\mathbf{A}_{S, k_{2}}\left(\mathbf{u}_{2}-\mathbf{r}_{S, k_{2}} \mathbf{i}_{S, k_{2}}-\boldsymbol{\Omega}_{1, k_{2}} \mathbf{\Psi}_{S, k_{2}}\right)+ \\
& +\mathbf{A}_{S R, k_{2}}\left(\mathbf{u}_{R, k_{2}}-\mathbf{r}_{R, k_{2}} \mathbf{i}_{R, k_{2}}\right)+\boldsymbol{\Omega}_{1, k_{2}} \mathbf{i}_{S, k_{2}}, \\
& \frac{d \mathbf{i}_{R, k_{2}}}{d t}= \\
& \quad \mathbf{A}_{R S, k_{2}}\left(\mathbf{u}_{S, k_{2}}-\mathbf{r}_{S, k_{2}} \mathbf{i}_{S, k_{2}}-\mathbf{\Omega}_{1, k_{2}} \mathbf{\Psi}_{S, k_{2}}\right)+ \\
& +\mathbf{A}_{R, k_{2}}\left(\mathbf{u}_{R, k_{2}}-\mathbf{r}_{R, k_{2}} \mathbf{i}_{R, k_{2}}\right)
\end{aligned}
$$

where: $\mathbf{A}_{1}, \mathbf{A}_{12}, \mathbf{A}_{21}, \mathbf{A}_{2}$ are coefficients depended on leakage inductances and magnetization inductances of transformer, $\mathbf{A}_{S, k_{1}}, \mathbf{A}_{S R, k_{1}}, \mathbf{A}_{R S, k_{1}}, \mathbf{A}_{R, k_{1}}$ are coefficients depended on leakage inductances and magnetization inductances of induction motors, $\mathbf{A}_{S, k_{2}}, \mathbf{A}_{S R, k_{2}}, \mathbf{A}_{R S, k_{2}}, \mathbf{A}_{R, k_{2}}$ are coefficients depended on leakage inductances and 
magnetization inductances of synchronous motors, $\boldsymbol{\Omega}_{k_{1}}, \boldsymbol{\Omega}_{1, k_{2}}$ are matrixes of angular velocities of induction motors and synchronous motors, respectively.

The terms for calculation of flux linkages in equations (19) - (22), taking into account (12) $-(16)$, may be given as follows $[1,4]$ :

$$
\begin{aligned}
\boldsymbol{\Psi}_{R, k_{1}}= & \mathbf{L}_{\sigma S, k_{1}} \mathbf{i}_{S, k_{1}}+\boldsymbol{\Pi}_{k_{1}}^{-1} \boldsymbol{\Psi}_{k_{1}}=\mathbf{L}_{\sigma S, k_{1}} \mathbf{i}_{S, k_{1}}+ \\
& +\tau_{k_{1}}^{-1}\left(\boldsymbol{\Pi}_{k_{1}}^{-1} \mathbf{i}_{S_{k_{1}}}+\mathbf{i}_{R_{k_{1}}}\right), \\
\boldsymbol{\Psi}_{S, k_{2}}= & \mathbf{L}_{\sigma S, k_{2}} \mathbf{i}_{S, k_{2}}+\boldsymbol{\Pi}_{1, k_{2}}^{-1} \boldsymbol{\psi}=\mathbf{L}_{\sigma S, k_{2}} \mathbf{i}_{S, k_{2}}+ \\
& +\boldsymbol{\Pi}_{1, k_{2}}^{-1} \boldsymbol{\tau}_{k_{2}}^{-1}\left(\boldsymbol{\Pi}_{1, k_{2}} \mathbf{i}_{S, k_{2}}+\mathbf{B}^{\mathrm{T}} \mathbf{i}_{R, k_{2}}\right) .
\end{aligned}
$$

From the third dependency in (6) the following relationships may be obtained:

$$
\frac{d \boldsymbol{\Psi}_{L}}{d t}=\frac{\partial \boldsymbol{\Psi}_{L}}{\partial \mathbf{i}_{L}} \frac{d \mathbf{i}_{L}}{d t}, \quad \mathbf{L}_{L}^{\partial} \equiv \frac{\partial \boldsymbol{\Psi}_{L}}{\partial \mathbf{i}_{L}}
$$

which may be used to derive the matrix equation of nonlinear load of transformer:

$$
\frac{d \mathbf{i}_{L}}{d t}=\boldsymbol{\alpha}_{L}^{\partial}\left(\mathbf{u}_{2}-\mathbf{R}\left(\mathbf{i}_{L}\right) \mathbf{i}_{L}\right), \quad \boldsymbol{\alpha}_{L}^{\partial}=\left[\mathbf{L}_{L}^{\partial}\right]^{-1} .
$$

For the load assembly (Fig. 1) it may be written:

$$
\mathbf{i}_{2}+\mathbf{i}_{L}+\sum_{k_{1}=1}^{M} \mathbf{i}_{S, k_{1}}+\sum_{k_{2}=M+1}^{N} \mathbf{i}_{S, k_{1}}=0 .
$$

As a consequence of time differentiation of equation (27), taking into account initial conditions and dependencies (18), (19), (21) and (26), the following dependency may be derived:

$$
\frac{d \mathbf{i}_{2}}{d t}+\frac{d \mathbf{i}_{L}}{d t}+\sum_{k_{1}=1}^{M} \frac{d \mathbf{i}_{S, k_{1}}}{d t}+\sum_{k_{2}=M+1}^{N} \frac{d \mathbf{i}_{S, k_{2}}}{d t}=0,
$$

which may be used to derive the voltage across the load circuit:

$$
\begin{aligned}
& \mathbf{u}_{2} \equiv \mathbf{V}=\left\{\mathbf{A}_{22}+\boldsymbol{\alpha}_{L}^{\partial}+\sum_{k_{1}=1}^{M} \mathbf{A}_{S, k_{1}}+\sum_{k_{2}=M+1}^{N} \mathbf{A}_{S, k_{2}}\right\}^{-1} \times \\
& \times\left\{\mathbf{A}_{22} \mathbf{r}_{2} \mathbf{i}_{2}-\mathbf{A}_{21}\left(\mathbf{u}_{1}-\mathbf{r}_{1} \mathbf{i}_{1}\right)+\boldsymbol{\alpha}_{L}^{\partial} \mathbf{R}\left(\mathbf{i}_{L}\right) \mathbf{i}_{L}-\right. \\
&-\sum_{k_{1}=1}^{M}\left[-\mathbf{A}_{S, k_{1}} \mathbf{r}_{S, k_{1}} \mathbf{i}_{S, k_{1}}+\mathbf{A}_{S R, k_{1}}\left(-\mathbf{u}_{R, k_{1}}-\boldsymbol{\Omega}_{k_{1}} \boldsymbol{\Psi}_{R, k_{1}}-\mathbf{r}_{R, k_{1}} \mathbf{i}_{R, k_{1}}\right)\right]- \\
&-\sum_{k_{2}=M+1}^{N}\left[\mathbf{A}_{S, k_{2}}\left(-\mathbf{r}_{S, k_{2}} \mathbf{i}_{S, k_{2}}-\boldsymbol{\Omega}_{1, k_{2}} \boldsymbol{\Psi}_{S, k_{2}}\right)+\right. \\
&\left.\left.+\mathbf{A}_{S R, k_{2}}\left(\mathbf{u}_{R, k_{2}}-\mathbf{r}_{R, k_{2}} \mathbf{i}_{R, k_{2}}\right)+\boldsymbol{\Omega}_{1, k_{2}} \mathbf{i}_{S, k_{2}}\right]\right\} .
\end{aligned}
$$

The electromagnetic torques of motors are given as follows $[1,4,10]$ : 


$$
\begin{aligned}
& M_{E M, k_{1}}=\sqrt{3} p_{0, k_{1}}\left(i_{S B, k_{1}} i_{R A, k_{1}}^{\Pi}-i_{S A, k_{1}} i_{R B, k_{1}}^{\Pi}\right) / \tau_{m, k_{1}}, \\
& M_{E M, k_{2}}=\sqrt{3} p_{0, k_{2}}\left(\Psi_{S B, k_{2}} i_{S A, k_{2}}-\Psi_{S A, k_{2}} i_{S B, k_{2}}\right),
\end{aligned}
$$

where $p_{0}$ is number of pole pairs of electric machines.

The system of differential equations (9) - (11), (17) - (22), (26) shall be integrated taking into account (23), (24), (29) - (31).

\section{Results of computer symulation}

The electrical system (Fig. 1), consisting of transformer, one drive based on synchronous motor and two drives based on induction motor, has been analysed numerically.

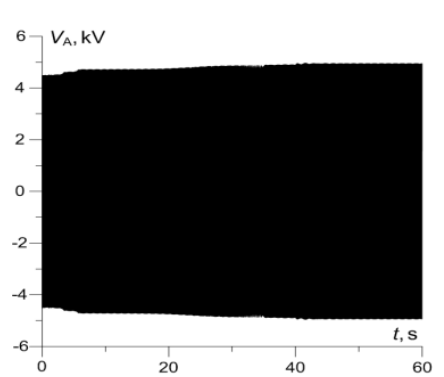

Fig. 2. Phase voltage of transformer secondary vs. time.

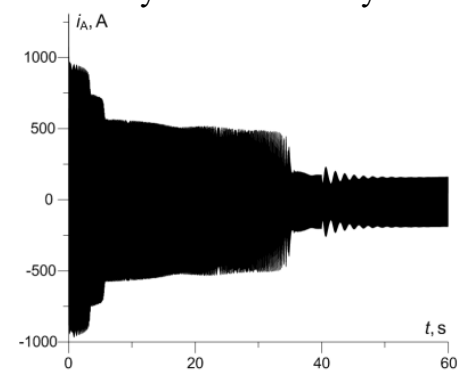

Fig. 3. Current of transformer secondary vs. time.

The graphs of A-phase voltage and A-phase current of transformer secondary versus time are shown in Figs. 2 and 3. The changes of voltages and currents over time characterize energetic state of the system. At the beginning of starting the motors a minimal voltage and maximal current occur in the system. The steady state voltage has rated value.

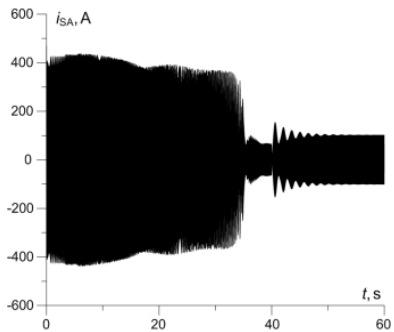

Fig. 4. Phase current of synchronous motor vs. time.

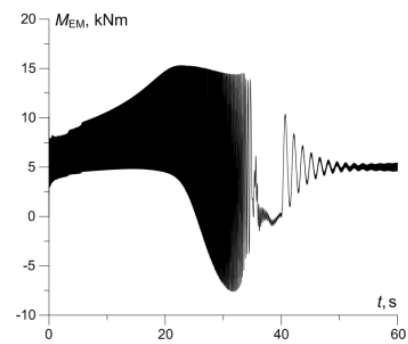

Fig. 6. Electromagnetic torque of synchronous motor vs. time.

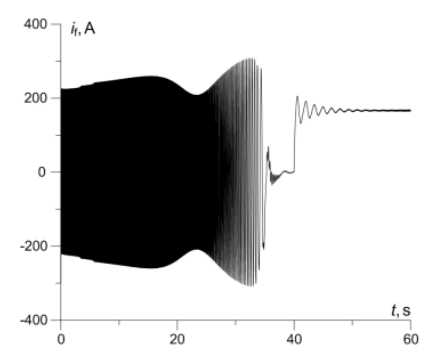

Fig. 5. Exciting current of synchronous motor vs. time.

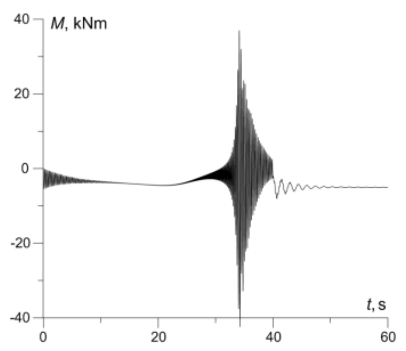

Fig. 7. Moment of elasticity in the clutch of synchronous drive vs. time. 
The exemplary time changes of function quantities of the drive based on synchronous motor are shown in Figs. 4 to 7 . At the time $t=40$ s the electromechanical oscillations are observed in the system. These oscillations are caused by synchronization of synchronous motor, whereas the moments of elasticity in transmission shafts are maximal at the time of achievement of subsynchronous speed.

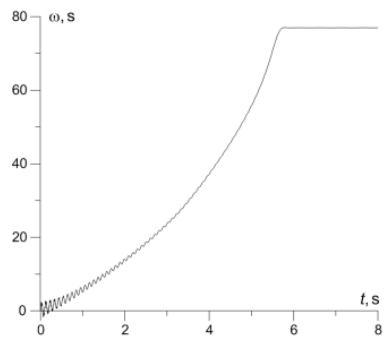

Fig. 8. Angular velocity of rotor of the first drive based on induction motor vs. time.

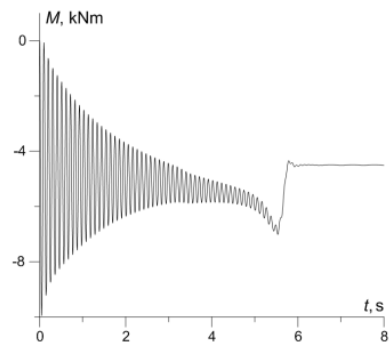

Fig. 10. Moment of elasticity in the clutch of the first drive based on induction motor vs. time.

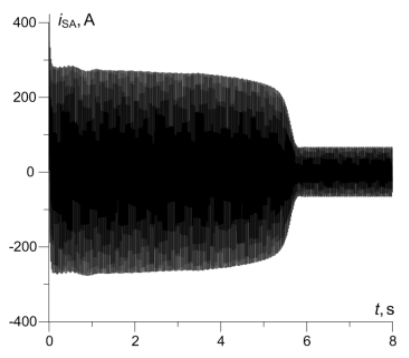

Fig. 12. A-phase current in a stator winding of the first induction motor.

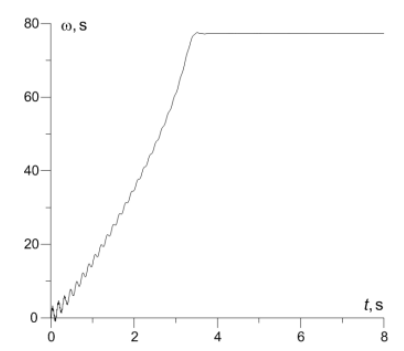

Fig. 9. Angular velocity of rotor of the second drive based on induction motor vs. time.

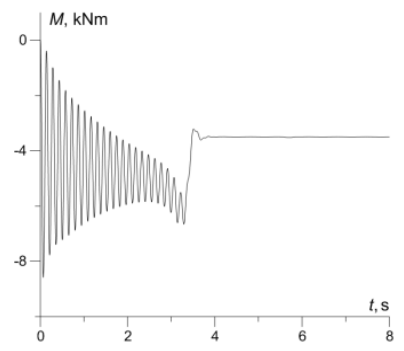

Fig. 11. Moment of elasticity in the clutch of the second drive based on induction motor vs. time.

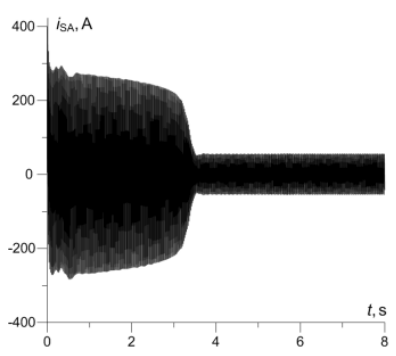

Fig. 13. A-phase current in a stator winding of the second induction motor.

The selected time changes of function quantities of both drives based on induction motor are shown in Figs. $8-13$. The comparison analysis of both drives shows different frequencies of mechanical oscillation caused by different parameters of elastic clutches adopted in numerical calculations. Transient currents during starting the motors shows the higher load of the first drive. 


\section{Conclusion}

The application of interdisciplinary variational approaches allows to formulate mathematical models for very complex electromechanical systems and power generation systems including electric load assemblies consisting of transformer, synchronous motors and induction motors with elastic shafts as well as active-inductive load, etc.

On the basis of the presented above results of computer simulation the following conclusions can be drawn:

a) complex physical processes occurring in electromechanical systems are dependent substantially on both processes occurring in each element of the system and interactions between all elements

b) improperly designed mechanical power transmission systems of electrical drives may lead to the increase of elastic moments as a consequence of resonant processes, which, in turn, may lead to the damage of the entire system.

\section{References}

1. Czaban A. Zasada Hamiltona-Ostrogradskiego w układach elektromechanicznych. Lwów: W-wo T. Soroki (2015)

2. A. Czaban, M. Lis Model matematyczny i analiza układu napędowego silnika indukcyjnego $\mathrm{z}$ długim elementem sprężystym dla parametrów rozłożonych Prace naukowe IMNPT Politechniki Wrocławskiej, Nr 66, 224 - 229 (2012)

3. A. Rusek, A. Chaban, M. Lis Mathematical Modelling of Transient States in a Drive System with a Long Elastic Element, Przegląd Elektrotechniczny, Nr 12b, 167 - 170 (2012)

4. Lis M. Modelowanie matematyczne procesów nieustalonych w elektrycznych układach napędowych o złożonej transmisji ruchu. Częstochowa. - W-wo Politechniki Częstochowskiej (2013)

5. A. Rusek Stany dynamiczne układów napędowych $\mathrm{z}$ silnikami indukcyjnymi specjalnego wykorzystania. Monografia. W-wo Politechniki Częstochowskiej, Częstochowa (2012)

6. White D.C., Woodson H.H. Electromagnetic Energy Conversion, New-York, John Wiley \& Sons, Inc, (1958)

7. Чабан В. И. Методы анализа электромеханических систем. - Львов: Вища школа,- 192 с. (1985)

8. Popenda A., Mathematical Modelling of Real Transmission Shafts and Mechanical Connections with Clearances, Przegląd Elektrotechniczny nr 1, 189-192, (2017)

9. Popenda A., Simple Mathematical Models of Transmission Shafts and Gear Trains. Electrical and Mechanical Circuits, Przegląd Elektrotechniczny nr 12, 137-140, (2016)

10. Popenda A., Modelowanie i symulacja dynamicznych stanów pracy układów napędowych do reaktorów polimeryzacji z silnikami indukcyjnymi specjalnego wykonania, Wydawnictwo Politechniki Częstochowskiej, Częstochowa (2011) 